\title{
Vanishing cecal polypoid mass lesion
}

\author{
Nazira Chatur MD FRCPC, Hugh J Freeman MD FRCPC
}

\section{CASE PRESENTATION}

A 53-year-old man was referred because of colonoscopic identification by a surgeon of a large cecal polyp, possibly amenable to endoscopic removal. During the colonoscopic evaluation, no cecal lesion was seen by two expert gastroenterologists despite excellent visualization of the cecum. Ileal and appendiceal orifices appeared normal. After photographs were taken to document an apparently normal cecum (Figure 1), a large colonic polypoid mass appeared to partially, then subsequently fully prolapsed into the cecum during the procedure from the ileocecal orifice (Figure 2). This was later removed by laparoscopic resection and proved to be a villous adenoma of the cecum.

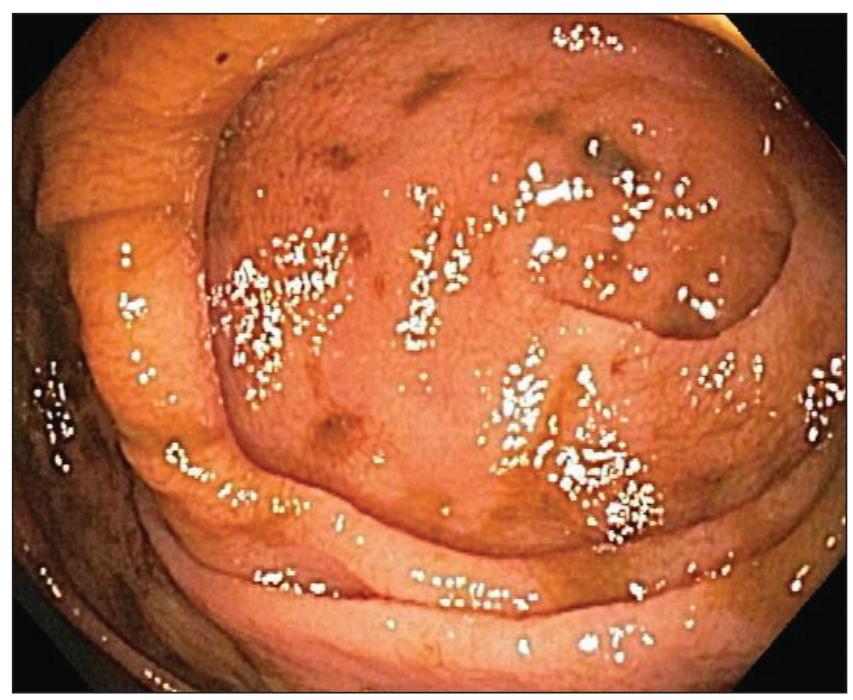

Figure 1) Normal cecum with no mass lesion

\section{DISCUSSION}

A few reports have documented intussusception of benign and malignant polypoid lesions in the ileocecal area of adults $(1,2)$. Usually, patients experience intermittent abdominal pain and distension, sometimes with nausea and vomiting, suggesting an obstructing lesion. In adults, a well-defined pathological abnormality is often evident and the intussusception is believed to be caused by a specific pathological lesion associated with a freely moving segment telescoping into an adjacent fixed or retroperitoneal segment. As a result, a relatively common site of intussusception is the ileocecal area (3).

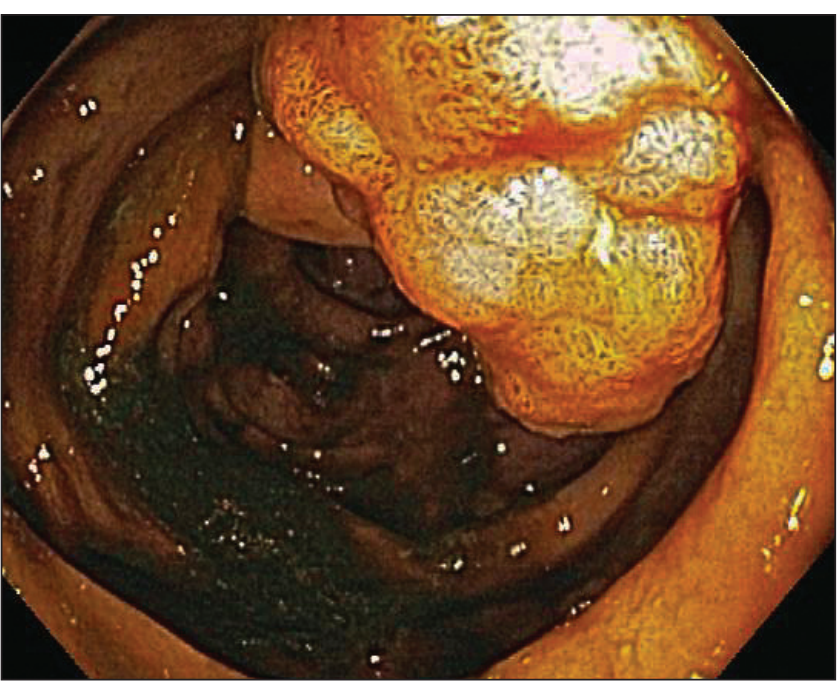

Figure 2) Fully prolapsed cecal mass lesion that proved to be a large villous adenoma

Department of Medicine, Division of Gastroenterology, University of British Columbia, Vancouver, British Columbia

Correspondence: Dr Hugh J Freeman, Division of Gastroenterology, University of British Columbia Hospital, 2211 Wesbrook Mall,

Vancouver, British Columbia V6T 1W5. Telephone 604-822-7216, fax 604-822-7236, email hugfree@shaw.ca

Received for publication October 5, 2011. Accepted October 11, 2011 
Most often, preoperative diagnosis includes imaging studies, which have historically involved barium enema studies and, more recently, computed tomographic imaging. Occasionally, an intussusception may be confirmed by colonoscopic evaluation. In adults, operative treatment is usually required because the cause often proves to be carcinoma, lymphoma or carcinoid tumour. In the present case, definition of a large cecal lesion was not immediately apparent to two expert endoscopists, possibly because of initial air insufflation in the presence of a mobile ileocecal lesion. While apparently rare, endoscopists performing routine diagnostic or screening colonoscopy should be aware of the potential for missing even large neoplastic appendiceal (4) or ileal orifice lesions.

\section{REFERENCES}

1. Hussien M, Gardiner K. Benign neoplastic polyp of the cecum as a rare cause of intussception in adults. Ulster Med J 1999;68:108-9.

2. Ibrahim D, Patel NP, Gupta M, Fox JC, Lotfipour S.

Ileocecal intussusception in the adult population: Case series of two patients. West J Emerg Med 2010;11:197-200.

3. Yakan S, Caliskan C, Makay O, Denecli AG, Korkut MA. Intussception in adults: Clinical characteristics, diagnosis and operative strategies. World J Gastroenterol 2009;15:1985-9.

4. Freeman HJ, Webber DL, Meneghetti AT. An appendiceal neoplastic lesion: Case report and implications for colonoscopic screening and surveillance. Can J Gastroenterol 2009;23:379-81.

The Canadian Journal of Gastroenterology is now considering a limited number of submissions for IMAGE OF THE MONTH. These will be based on endoscopic, histological, radiological and/or patient images, which must be anonymous with no identifying features visible. The patient must consent to publication, and the consent must be submitted with the manuscript. All manuscripts should be practical and relevant to clinical practice, and not simply a case report of an esoteric condition. The text should be brief, structured as CASE PRESENTATION and DISCUSSION, and not more than 700 words in length. A maximum of three to four images can be submitted, and the number of references should not exceed five. The submission may be edited by our editorial team. 


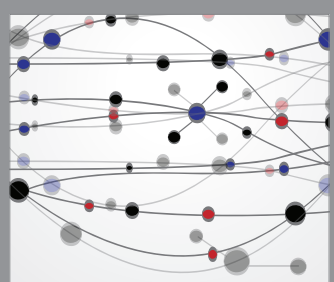

The Scientific World Journal
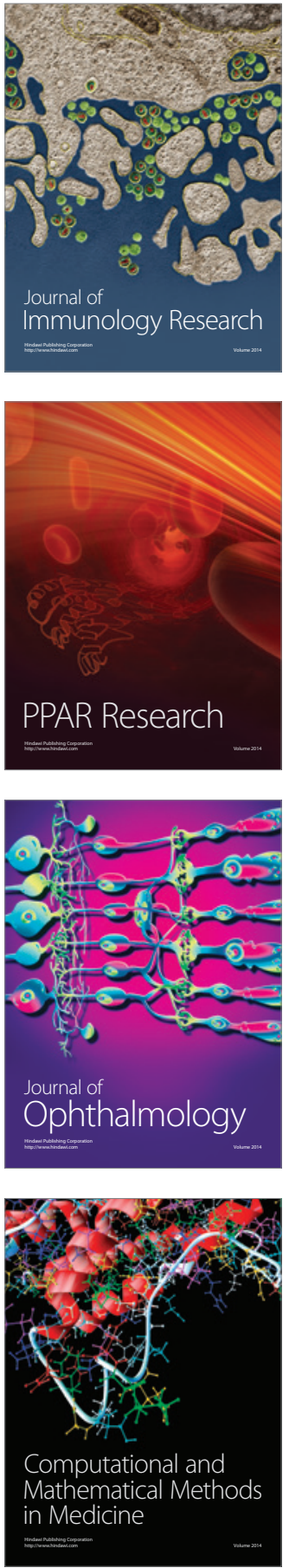

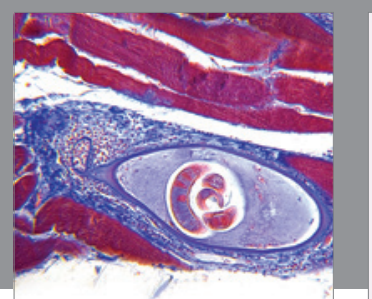

Gastroenterology Research and Practice

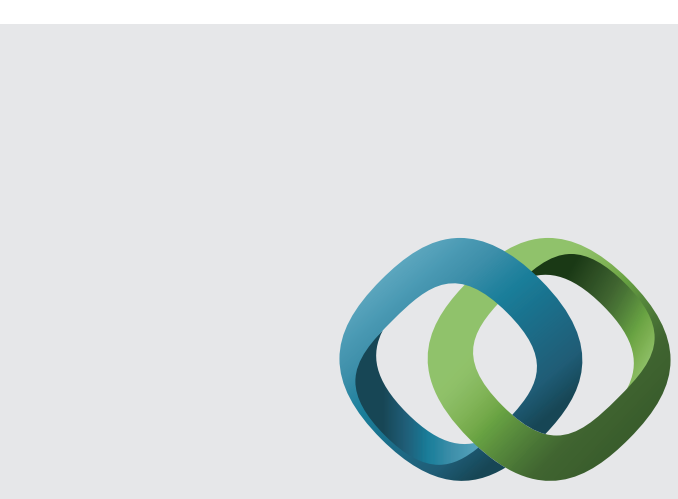

\section{Hindawi}

Submit your manuscripts at

http://www.hindawi.com
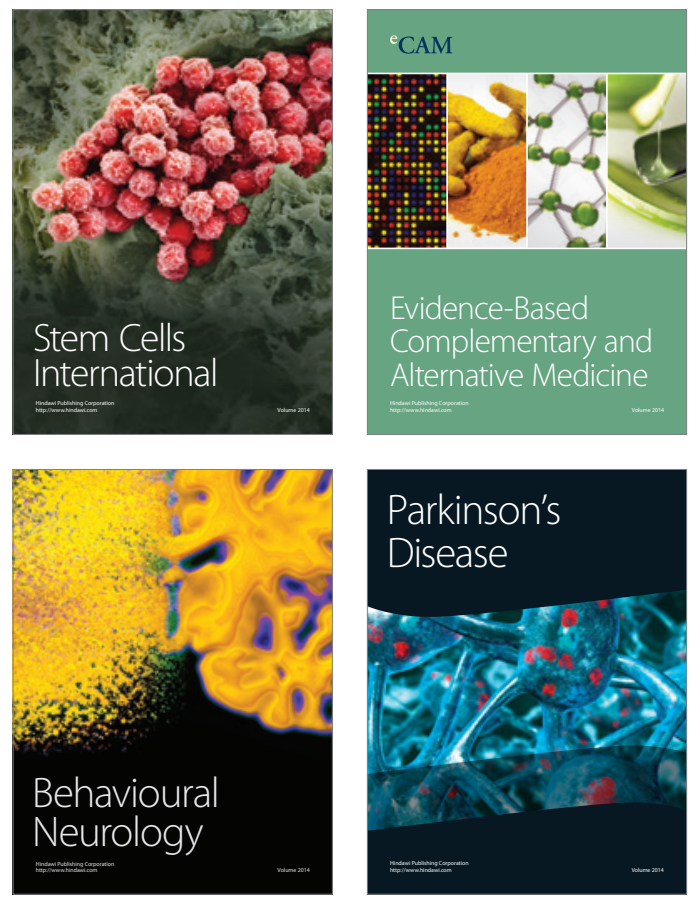
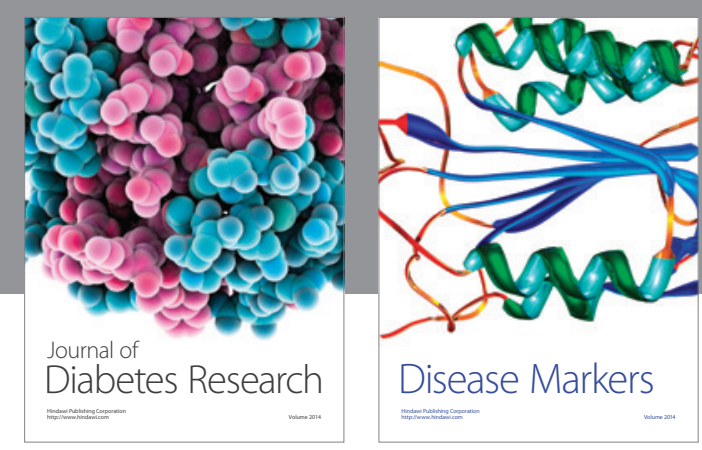

Disease Markers
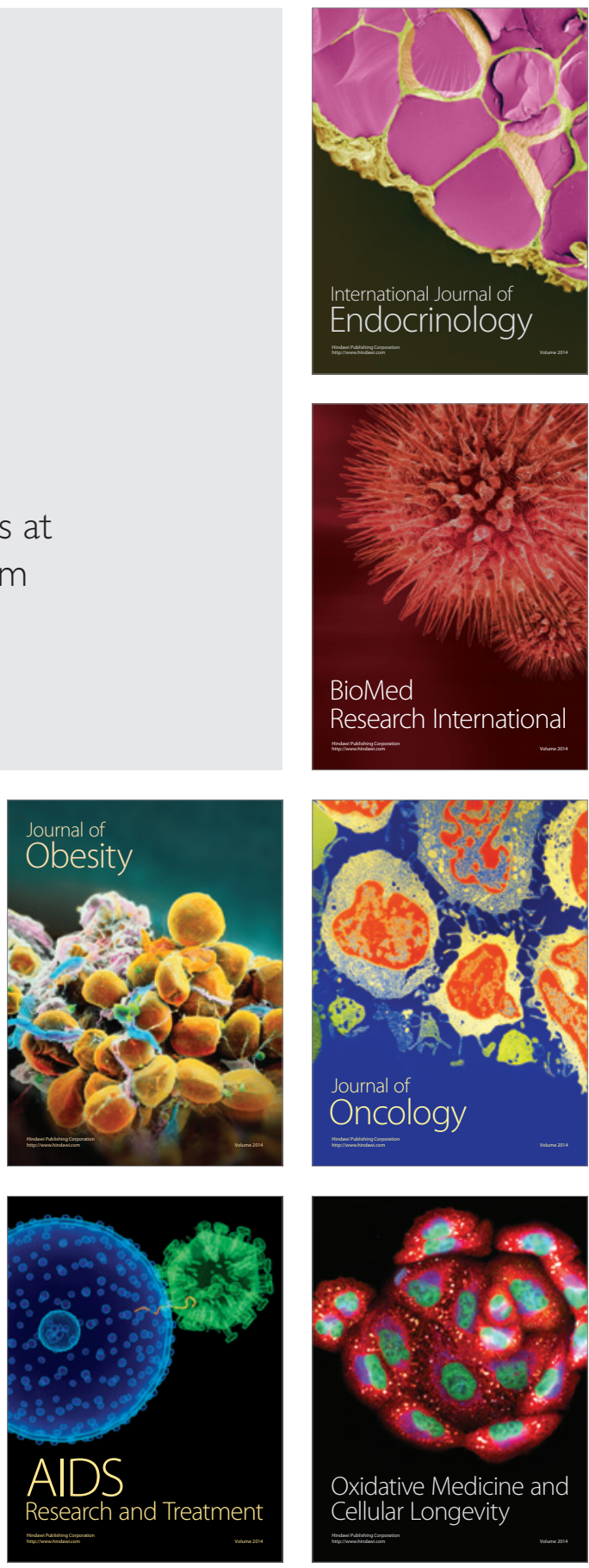